\title{
From knowing to doing: it takes a village
}

\author{
Karen Kotila, ${ }^{1}$ Kristian Thorborg, ${ }^{2}$ Thomas Bandholm, ${ }^{3}$ Anders Vinther, ${ }^{4}$ \\ Carsten B Juhl, ${ }^{4,5}$ Bente S Andersen ${ }^{1,6}$
}

\section{FROM KNOWING TO DOING: IT TAKES A VILLAGE-TRANSLATION, DISSEMINATION, SHARING}

'There is no guarantee that research will find its way to where it is needed. Or that it will even be read, cited or circulated'. ${ }^{1}$ For many years, knowledge management has started and ended with the publication of an article, or the rare chance of a lecture or speech at a conference attended by other researchers. Now, in the halcyon days of social media, we still need to cultivate knowledge management, which in the sports medicine context is translation, dissemination and sharing of knowledge. At a time when evidence-based practice competes on the social media with sports superstars who attribute success to popular quick fixes, we need to take a hard, critical view at our knowledge management approaches.

\section{HIGH-QUALITY RESEARCH AND COLLABORATION IS THE FOUNDATION}

Within the sports medicine/sportsphysiotherapy community, BJSM is a pioneer in the field of knowledge sharing, using a multimedia portal approach. BJSM has greatly influenced and further developed the internationally collaborative management of knowledge. The journal also takes responsibility for educating its readers and influence researchers because, first of all, research has to be of great quality before knowledge translation and sharing becomes relevant. The PREPARE Trial guide by Professor

\footnotetext{
${ }^{1}$ Danish Society of Sports Physical Therapy, Odense, Denmark

${ }^{2}$ Department of Orthopedic Surgery, AmagerHvidovre Hospital, Sports Orthopaedic Research Center-Copenhagen (SORC-C), Arthroscopic Center, Copenhagen University Hospital, Amager-Hvidovre, Hvidovre, Copenhagen, Denmark

${ }^{3}$ Physical Medicine \& Rehabilitation ResearchCopenhagen (PMR-C), Department of Physio- and Occupational Therapy, Department of Orthopaedic Surgery, Clinical Research Centre, Amager-Hvidovre Hospital, University of Copenhagen, Copenhagen, Denmark

${ }^{4}$ Department of Rehabilitation, Herlev and Gentofte Hospital, Herlev, Denmark

${ }^{5}$ Department of Sports Science and Clinical

Biomechanics, University of Southern Denmark, Odense $M$, Denmark

${ }^{6}$ Physiotherapy Education, University College Capital, Copenhagen, Denmark
}

Correspondence to Karen Kotila, Danish Society of Sports Physical Therapy, Odense, Denmark; karen.evnbasketball@gmail.com
Thomas Bandholm and colleagues is a 'How to' guide for the early-career researcher and all others who want to design their trial research according to recent developments within trial transparency and reduce research waste initiatives (see page 1494).

International collaboration is inevitably part of the future of research. Umbrella reviews and network meta-analyses, where all treatments for a given condition or disease and all the possible comparisons between them are examined, are two examples of international collaboration, where multiple people are working on the same problem and exchanging ideas. Dr John Ioannidis, in his editorial (see page 1456), argues that even with all the pitfalls of confounding and selection bias, evidence synthesis of obtained raw data from clinical research can become a reality.

In an umbrella review, Professor Urho M Kujala presents one example of 'Next generation evidence synthesis' (see page 1459). The objective is to summarise all meta-analyses of randomised controlled trials that have evaluated the effects of exercise therapy on functional capacity in patients with chronic diseases.

\section{WHEN IS A STUDY CLINICALLY RELEVANT?}

How do you even know if the results of a particular study are important to your team, your patients or your community? Professor Mansournia, from the esteemed University of Tehran, and colleagues (see page 1454) take us through the second of a series of editorials that will help clinicians and team staff interpret studies more critically and confidently.

\section{MAKING KNOWLEDGE STICK}

Yet another level of knowledge management is reaching beyond the sports medicine community to our athletes and citizens. Here, we are confronted with another challenge: How do we make knowledge stick? Excellent sports exercise and medicine projects initiated by Professor Jiri Dvorak and colleagues should get your attention as well as the infographic on the substantial injury preventive effect from the $11+$ programme (see page 1493) and the ' 11 for Health' football-based programme (see page 1483). The latter was developed in 2009 as a way to engage with 10-year-old to 13-year-old children in sub-Saharan Africa, to increase their levels of physical activity and health knowledge. Translated into six languages and delivered successfully in 12 countries, the authors considered that ' 11 for Health' had the potential to address health concerns associated with non-communicable diseases (NCDs) in Europe.

\section{SUCCESS IN DENMARK}

The 11 for Health was implemented in numerous Danish schools to increase children's levels of physical activity and their knowledge about NCDs. This was a collaboration with the Danish Football Association and the Danish Ministries of Health, Education and Sport. The implementation and effectiveness of these programme are still being studied and pursued in Denmark due to their promise in fighting injury illness and disease but it is sad to see that these programmes lost their support within FIFA and are no longer part of the FIFA medical committee's strategy.

In this first Danish issue, we take you on a journey through the levels of knowledge management. Knowledge management can be quite a challenge for an individual clinical society. We are very fortunate to have in the Danish Society of Sports Physical Therapy and among our collaborative partners a large group of people who strive to make this mission successful. A great asset of our group is its diversity. The broad palette of society members, the clinical lecturers that teach the upcoming sports physical therapists, the team behind our sports medicine catalogues 'Clinical Evidence and Guidance', the board members, the editorial board of Danish Sports Medicine and last but not least the annual teams behind our 'flagship' \#sportskongres all practice the art of working together as a village to provide value for our society members.

\section{Competing interests None declared.}

Provenance and peer review Commissioned; internally peer reviewed.

(C) Article author(s) (or their employer(s) unless otherwise stated in the text of the article) 2017. All rights reserved. No commercial use is permitted unless otherwise expressly granted.

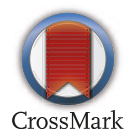

To cite Kotila K, Thorborg K, Bandholm T, et al. Br J Sports Med 2017;51:1447.

Br J Sports Med 2017;51:1447. doi:10.1136/bjsports-2017-098322

\section{REFERENCE}

1 Hansted AB. Collaboration: on the edge of a new paradigm? Roskilde: Roskilde Universitet, 2016. 